\title{
Effect of Rearing Temperatures during Embryonic Development on the Phenotypic Sex in Zebrafish (Danio rerio)
}

\author{
H. Abozaid S. Wessels G. Hörstgen-Schwark \\ Department of Animal Sciences, Aquaculture and Water Ecology, Göttingen, Germany
}

\section{Key Words}

Embryogenesis · Temperature-dependent sex

determination $\cdot$ Zebrafish

\begin{abstract}
In zebrafish, Danio rerio, a polygenic pattern of sex determination or a female heterogamety with possible influences of environmental factors is assumed. The present study focuses on the effects of an elevated water temperature $\left(35^{\circ} \mathrm{C}\right)$ during the embryonic development on sex determination in zebrafish. Eggs derived from 3 golden females were fertilized by the same mitotic gynogenetic male and exposed to a water temperature of $35^{\circ} \mathrm{C}$, applied from 5 to $10 \mathrm{~h}$ post fertilization (hpf), from 5 to $24 \mathrm{hpf}$, and from 5 to $48 \mathrm{hpf}$, which correspond to the following developmental stages: gastrula, gastrula to segmentation, and gastrula to pharyngula stage, respectively. Hatching and survival rates decreased with increasing exposure to high water temperatures. Reductions in the hatching and survival rates were not responsible for differences in sex ratios. Accordingly, exposition of the fertilized eggs to a high temperature $\left(35^{\circ} \mathrm{C}\right)$ leads to an increase of the male proportion from $22.0 \%$ in the controls to a balanced sex ratio $(48.3,47.5$, and $52.6 \%)$ in the gastrula, segmentation, and pharyngula groups, respectively. These results prove the possibility to change the pathway of sexual determination during early embryonic stages in zebrafish by exposure to a high water temperature.

Copyright $\odot 2011$ S. Karger AG, Basel
\end{abstract}

Sex determination and differentiation processes in fish are complex and labile mechanisms under the control of genetic and/or environmental factors [Conover, 2004; Ospina-Alvarez and Piferrer, 2008; Baroiller et al., 2009a]. Water temperature is the most relevant environmental factor affecting the sex determination process in fish [Devlin and Nagahama, 2002; Baroiller et al., 2009b]. Although the zebrafish is considered the most important model to study developmental genetics and biology as well as biotechnology in vertebrates [Kimmel, 1989; Barinaga, 1990; Kahn, 1994; Fishman, 2001; Grunwald and Eisen, 2002; Rubinstein, 2003; Amsterdam and Hopkins, 2006], the mechanism of sex determination is largely unknown. Neither sex chromosomes nor sex-linked mutations or markers have been observed so far [Sola and Gornung, 2001; Traut and Winking, 2001; Wallace and Wallace, 2003]. Recently, Tong et al. [2010] reported that sex determination in zebrafish is controlled by female-dominant genetic factors (ZW). In zebrafish, exposure to high water temperatures during the sex differentiation period (15-25 days post hatching (dph)) leads to sex-reversal of genotypic females to phenotypic males, proving the prevalence of a temperature-dependent sex determination [Uchida et al., 2004]. In other species, such as Oreochromis niloticus or Oreochromis aureus, the phenotypic sex is under the control of major genetic factors located on LG1 or LG3 (XX/XY or ZZ/ZW), which can be overridden by minor genetic factors (parental effects) and tem-

\section{KARGER \\ Fax +4161306 1234 \\ E-Mail karger@karger.ch}

www.karger.com
(C) 2011 S. Karger AG, Basel

$1661-5425 / 11 / 0055-0259 \$ 38.00 / 0$

Accessible online at:

www.karger.com/sxd
Stephan Wessels

Department of Animal Sciences, Aquaculture and Water Ecology

Albrecht-Thaer-Weg 3

DE-37075 Göttingen (Germany)

Tel. +49551395606, E-Mail swessel@gwdg.de 
perature during a critical period [Cnaani et al., 2008; Baroiller et al., 2009a]. Recently, gonadal sex reversal was even induced during embryogenesis by increasing the incubation temperature in Nile tilapia (Oreochromis niloticus) and medaka (Oryzias latipes) [Rougeot et al., 2008; Selim et al., 2009]. However, little information exists about exposure to high water temperatures during the early developmental stages and its effects later on in sex differentiation in zebrafish. Therefore, the aim of our study was to investigate the influence of an elevated water temperature $\left(35^{\circ} \mathrm{C}\right)$ on the sex determination process during different early developmental stages, the gastrula stage (5-10 h post fertilization (hpf)), segmentation stage (5-24 hpf), and pharyngula stage (5-48 hpf), of embryonic development in zebrafish.

\section{Material and Methods}

\section{Breeders and Egg Collection}

The experimental population of zebrafish, Danio rerio, used in the present experiment was a golden (gol) strain, which is defined to lack the melanophore pigmentation resulting in a yellow coloration with faint yellow stripes [Lamason et al., 2005]. This strain was used in earlier studies and maintained according to the description of Hörstgen-Schwark [1993]. All experiments were conducted at the recirculation system of the Division of Animal Sciences, Göttingen University, Germany.

\section{Thermal Treatment}

Fertilized eggs were derived from a mating of a mitotic gynogenetic male to 3 normal females. Each of the half-sib families was generated in duplicate using the same parents. Numbers of fertilized eggs were in the range of 336-940 per family. The eggs from each half-sib family were divided in equal proportions into 4 groups, a control group incubated at $28^{\circ} \mathrm{C}$ and 3 treatment groups. The treatment groups were incubated at $35^{\circ} \mathrm{C}$ from 5 to $10 \mathrm{hpf}$, from 5 to $24 \mathrm{hpf}$, or from 5 to $48 \mathrm{hpf}$. The treatment durations correspond to the following developmental stages: (a) gastrula stage, (b) gastrula to segmentation stage, and (c) gastrula to pharyngula stage [Kimmel et al., 1995]. Thus, the 3 treatment groups will be referred to as gastrula, segmentation, and pharyngula group throughout the manuscript. The incubation system was equipped with a heating system (Biotherm 2000). Water temperature was checked 3 times a day during the experimental periods. After finishing the thermal treatments, all groups were kept at $28^{\circ} \mathrm{C}$ in Petri dishes (diameter $9 \mathrm{~cm}$, max. 100 eggs/dish) until hatching. Dead eggs were removed after 1, 5, 10, 24, and $48 \mathrm{hpf}$. The hatching ( $72 \mathrm{hpf}$ ) and survival rates ( $90 \mathrm{dpf}$ ) were determined by counting the number of fish alive in all experimental groups. Thereafter, the hatched fry were transferred to 5-liter containers.

\section{Rearing of Juveniles}

Hatching and rearing of experimental fish were carried out according to standard procedures developed by Von Hertell et al. [1990]. Oxygen was maintained around 6 ppm (minimum), the
$\mathrm{pH}$ value of water was $8.0 \pm 0.2$, ammonia and nitrite concentrations were $0.02 \mathrm{mg} / 1 \pm 0.01$ and $0.01 \mathrm{mg} / 1 \pm 0.01$, respectively. In the recirculation system a 12-hour day/night rhythm was applied. First feeding started $6 \mathrm{dpf}$ with artemia and artificial food (Tetramin, ad lib.) until the fish reached sexual maturation (90 dpf). All fish were sacrificed using a lethal dose of anesthetic (2-phenoxyethanol). The phenotypic sex of all fish was determined by microscopical examination of the gonads at $90 \mathrm{dpf}$. Therefore, gonad tissue was removed and squashed with a cover slide, and the gonad samples were prepared for microscopical observation with an optical light microscope at $40 \times$ magnification. Sex identification was based upon the existence of oocytes in the females and the lobular morphology of the testis in the males.

\section{Statistical Analysis}

The sex ratios were analysed by fitting a generalized linear mixed model using the GLIMMIX macro (binominal error distribution, logit function) in SAS version 9.1, with sex coded as a binary trait $(0=$ male, $1=$ female) [McLean et al., 1991]. As a fix factor the treatment and as random factors the family and the replicate were included in the model. Effects on hatching and survival rates were analyzed using a generalized linear model (Proc GLM) in SAS. Differences between sex ratios of treatment and control groups were tested for significance using a $2 \times 2$ contingency table with a $\chi^{2}$ test for balanced groups or Fisher's exact test for unbalanced groups and male or female frequencies $<5$. To account for the variable number of offspring per treatment group and replicate, mean sex ratios were weighted according to the number of offspring. In order to test for differential mortality in the treatment groups, the observed frequencies of males (n males) and females ( $\mathrm{n}$ females) were multiplied with the survival rate (\% survival) in the corresponding full-sib control to obtain the theoretical number of surviving fry $\left(\mathrm{n}_{\text {theor }}\right)$. Subsequently, the difference between the theoretical number of fish $\left(\mathrm{n}_{\text {theor }}\right)$ and the observed number of males (n males) was calculated to obtain the theoretical number of females, if all dead fish were females ( $\mathrm{n}_{\text {theor }}-\mathrm{n}$ males $=\mathrm{n}_{\text {theor }}$ females). Accordingly, the theoretical number of males ( $\mathrm{n}_{\text {theor }}$ males) was calculated, if all dead fish were assumed to be males ( $\mathrm{n}_{\text {theor }}-\mathrm{n}$ females $=\mathrm{n}_{\text {theor }}$ males). Fisher's exact test was applied to test the observed against the theoretical frequencies in 2 scenarios: (a) all dead fish were males and (b) all dead fish were females.

\section{Results}

\section{Effect of Early Temperature Treatment on Hatching} and Survival Rates in Zebrafish

The hatching and survival rates tended to decrease with increasing exposure to a high water temperature $\left(35^{\circ} \mathrm{C}\right)$ in the gastrula (5-10 hpf), segmentation (5-24 hpf), and pharyngula group (5-48 hpf) (table 1). The control groups had the highest mean values for hatching and survival rates with 27.14 and $22.18 \%$, respectively. The mean hatching and survival rates $(6.95$ and $4.83 \%)$ in the pharyngula group were significantly $(\mathrm{p}<0.05)$ different from the control, the gastrula, and the segmentation 
Table 1. Effect of high water temperature $\left(35^{\circ} \mathrm{C}\right)$ during the embryonic development from 5 to 10 hpf, from 5 to 24 hpf, and from 5 to $48 \mathrm{hpf}$ on hatching and survival rates $(90 \mathrm{dpf})$ of zebrafish

\begin{tabular}{|c|c|c|c|c|c|c|c|c|c|c|}
\hline \multirow[t]{2}{*}{ Family } & \multirow[t]{2}{*}{ Rep } & \multirow[t]{2}{*}{$\mathrm{N}$} & \multicolumn{4}{|c|}{ Hatching rates, $\%(0-72 \mathrm{hpf})$} & \multicolumn{4}{|c|}{ Survival rates, \% (0-90 dpf) } \\
\hline & & & control & $5-10 \mathrm{hpf}$ & $5-24 \mathrm{hpf}$ & 5-48 hpf & control & $5-10 \mathrm{hpf}$ & $5-24 \mathrm{hpf}$ & $5-48 \mathrm{hpf}$ \\
\hline 1 & 1 & 366 & 56.82 & 49.41 & 30.16 & 10.45 & 46.59 & 45.88 & 30.16 & 8.96 \\
\hline 1 & 2 & 524 & 11.45 & 6.87 & 6.87 & 3.05 & 9.16 & 5.34 & 6.11 & 1.53 \\
\hline 2 & 1 & 940 & 19.57 & 16.17 & 14.47 & 7.66 & 18.72 & 14.47 & 11.06 & 6.81 \\
\hline 2 & 2 & 740 & 21.08 & 15.68 & 15.68 & 2.70 & 17.30 & 15.68 & 13.51 & 1.62 \\
\hline 3 & 1 & 364 & 24.18 & 18.68 & 17.58 & 14.29 & 18.68 & 14.29 & 10.99 & 7.69 \\
\hline 3 & 2 & 336 & 29.76 & 17.86 & 13.10 & 3.57 & 22.62 & 16.67 & 11.90 & 2.38 \\
\hline$\overline{\mathrm{x}} \pm \mathrm{SD}$ & & 545 & $27.14^{\mathrm{a}} \pm 15.7$ & $20.78^{\mathrm{a}} \pm 14.7$ & $16.31^{\mathrm{a}, \mathrm{b}} \pm 7.7$ & $6.95^{\mathrm{b}} \pm 4.7$ & $22.18^{\mathrm{a}} \pm 12.8$ & $18.72^{\mathrm{a}} \pm 13.9$ & $13.96^{\mathrm{a}, \mathrm{b}} \pm 8.3$ & $4.83^{\mathrm{b}} \pm 3.4$ \\
\hline
\end{tabular}

Fertilized were eggs derived from repeated matings between a mitotic gynogenetic male and 3 different females.

Mean values with a different superscript letter were significantly different at a level of $\mathrm{p}<0.05$, d.f. $=1$.

$\mathrm{N}$ = Initial egg number; Rep = replication; $\mathrm{SD}$ = standard deviation.

group. No significant differences could be observed between the control, gastrula, and segmentation groups. Furthermore, repeated matings of the same parents resulted in highly repeatable hatching and survival rates in the control and treatment groups of family 2 and 3. Only the second replicate of the family 1 showed a decrease of the hatching and the survival rate (45.3 and $37.4 \%$ ), which might be attributed to low egg quality during spawning (table 1).

\section{Effect of Early Temperature Treatment on Sex Ratios in Zebrafish}

The overall male proportion in the control group was $22.0 \pm 6.6 \%$. The sex ratio in the control group differed significantly from a $1: 1$ distribution $(\mathrm{p}<0.001)$. However, exposition of eggs to a high water temperature $\left(35^{\circ} \mathrm{C}\right)$ during the embryonic stages lead to a significant increase of the male proportion from $22.0 \%$ in the control groups to balanced sex ratios $(48.3,47.5$, and $52.6 \%)$ in the gastrula, segmentation, and pharyngula group, respectively. Increasing the time of exposure from 5-10 hpf to 5-24 hpf or to 5-48 hpf did not lead to significant differences of sex ratios among the treatment groups. Weighting the mean sex ratios by the number of sexed individuals gave values comparable to the observed sex ratios (table 2). Repeated matings of the same parents gave almost equal sex ratios, both in the control and the treatment groups. No differential mortalities could be observed in the gastrula and segmentation group, when the observed and theoretical frequencies of males and females were compared (online suppl. table 1; for all online suppl. material, see www.karger.com/doi/10.1159/000330120). In the pharyngula group both scenarios, (a) all dead fish were assumed to be male and (b) all dead fish were assumed to be female, resulted in significant differences between the observed and the theoretical frequencies of males and females in one replicate of 2 families (family 1 and 2, replicate 1 ). In the second replicate of family 2 , a significant difference could only be detected if the dead fish were assumed to be female (table 2).

\section{Discussion}

The sex determining system in zebrafish shows a high plasticity, and no sex chromosomes have been identified [Traut and Winking, 2001; Wallace and Wallace, 2003; Orban et al., 2009]. Recently, a female heterogametic system $(\mathrm{ZZ/ZW})$ was reported in zebrafish [Tong et al., 2010]. Before, the sex determination mechanism in zebrafish has been described as multigenic with possible weak secondary influences from environmental factors [Orban et al., 2009]. The extent of interaction between major and minor genetic and environmental factors is still unknown in zebrafish, but it might differ within and between populations, as observed in Nile tilapia [Tessema et al., 2006].

Elevated water temperature during sex differentiation (15-25 dpf) leads to significant effects on the phenotypic sex of genetic all-female progenies [Uchida et al., 2004]. According to Shang et al. [2006], hypoxia can also affect the sex differentiation and sexual development of zebrafish. The timing and duration of the water temperature treatment is of critical importance to induce phenotypic sex reversal in fishes [Piferrer, 2001]. Generally in fish, little information is provided about the effects of water 
Table 2. Effect of high water temperature $\left(35^{\circ} \mathrm{C}\right)$ during the embryonic development from 5 to 10 hpf, from 5 to $24 \mathrm{hpf}$, and from 5 to $48 \mathrm{hpf}$ on sex ratios of zebrafish

\begin{tabular}{|c|c|c|c|c|c|c|}
\hline Treatment & Family & Replicate & $\mathrm{N}$ sexed & $\%$ Males & $\chi^{2}$ & $\%$ Males weighted \\
\hline Control & $\begin{array}{l}1 \\
1 \\
2 \\
2 \\
3 \\
3 \\
\overline{\mathrm{x}} \pm \mathrm{SD}\end{array}$ & $\begin{array}{l}1 \\
2 \\
1 \\
2 \\
1 \\
2\end{array}$ & $\begin{array}{l}41 \\
12 \\
44 \\
32 \\
17 \\
19\end{array}$ & $\begin{array}{l}21.95 \\
16.67 \\
27.27 \\
28.13 \\
11.76 \\
26.32 \\
22.01 \pm 6.59\end{array}$ & $\begin{array}{r}12.90^{\mathrm{b}} \\
5.33^{\mathrm{a}} \\
9.09^{\mathrm{b}} \\
6.12^{\mathrm{a}} \\
9.94^{\mathrm{b}} \\
4.20^{\mathrm{a}} \\
31.32^{\mathrm{b}}\end{array}$ & $\begin{array}{l}20.75 \\
27.63 \\
19.44 \\
25.32\end{array}$ \\
\hline $5-10 \mathrm{hpf}$ & $\begin{array}{l}1 \\
1 \\
2 \\
2 \\
3 \\
3 \\
\overline{\mathrm{x}} \pm \mathrm{SD}\end{array}$ & $\begin{array}{l}1 \\
2 \\
1 \\
2 \\
1 \\
2\end{array}$ & $\begin{array}{r}29 \\
7 \\
34 \\
29 \\
13 \\
14\end{array}$ & $\begin{array}{l}38.46 \\
57.14 \\
52.94 \\
44.83 \\
46.15 \\
50.00 \\
48.25 \pm 6.57\end{array}$ & $\begin{array}{l}0.31 \\
0.14 \\
0.12 \\
0.31 \\
0.08 \\
0.00 \\
0.12\end{array}$ & $\begin{array}{l}42.09 \\
49.21 \\
48.15 \\
46.94\end{array}$ \\
\hline $5-24 \mathrm{hpf}$ & $\begin{array}{l}1 \\
1 \\
2 \\
2 \\
3 \\
3 \\
\overline{\mathrm{x}} \pm \mathrm{SD}\end{array}$ & $\begin{array}{l}1 \\
2 \\
1 \\
2 \\
1 \\
2\end{array}$ & $\begin{array}{r}38 \\
8 \\
26 \\
25 \\
10 \\
10\end{array}$ & $\begin{array}{l}47.37 \\
50.00 \\
53.85 \\
44.00 \\
50.00 \\
40.00 \\
47.54 \pm 4.92\end{array}$ & $\begin{array}{l}0.11 \\
0.00 \\
0.15 \\
0.36 \\
0.00 \\
0.40 \\
0.24\end{array}$ & $\begin{array}{l}47.83 \\
49.02 \\
45.00 \\
47.86\end{array}$ \\
\hline $5-48 \mathrm{hpf}$ & $\begin{array}{l}1 \\
1 \\
2 \\
2 \\
3 \\
3 \\
\overline{\mathrm{x}} \pm \mathrm{SD}\end{array}$ & $\begin{array}{l}1 \\
2 \\
1 \\
2 \\
1 \\
2\end{array}$ & $\begin{array}{r}6 \\
2 \\
16 \\
3 \\
7 \\
2\end{array}$ & $\begin{array}{l}50.00 \\
50.00 \\
56.25 \\
66.67 \\
42.86 \\
50.00 \\
52.63 \pm 8.07\end{array}$ & $\begin{array}{l}0.00 \\
0.00 \\
0.25 \\
0.33 \\
0.14 \\
0.00 \\
0.27\end{array}$ & $\begin{array}{l}50.00 \\
57.90 \\
44.45 \\
52.77\end{array}$ \\
\hline
\end{tabular}

Fertilized eggs were derived from repeated matings between a mitotic gynogenetic male and 3 different females.

$\chi^{2}=$ value for the deviation from a 1:1 distribution. \% Males weighted $=\mathrm{n}$ males sexed (replicate 1$) \times$ male $\%($ replicate 1$)+\mathrm{n}$ males sexed (replicate 2$) \times$ male $\%$ (replicate 2 )/n sexed per family. ${ }^{\mathrm{a}} \mathrm{p}<0.05,{ }^{\mathrm{b}} \mathrm{p}<0.001$, d.f. $=1 . S D=$ Standard deviation. d.f. $=1$.

temperature on the sex determination process before hatching [Rougeot et al., 2008]. Therefore, the present study focused on the effects of an elevated water temperature $\left(35^{\circ} \mathrm{C}\right)$ during the embryonic development on the phenotypic sex in zebrafish.

Elevated water temperatures during the embryonic development are known to cause abnormalities in early development and increase the physical stress during these stages [Heugens et al., 2001]. In the present investigation, extending the exposure period of embryos to a high water temperature $\left(35^{\circ} \mathrm{C}\right)$ from $5-10 \mathrm{hpf}$ or $5-24 \mathrm{hpf}$ to $5-48$ hpf significantly reduced the hatching and survival rate (table 1). Irrespective of the hatching and survival rates, the present study proves that it is possible to change the sex ratio during zebrafish embryogenesis through exposure of eggs to an elevated water temperature $\left(35^{\circ} \mathrm{C}\right)$. Differential mortalities of females or males could not be observed in the gastrula and segmentation groups. In the pharyngula group, only 1 out of 6 replicates differed significantly for a scenario where all dead fish were females, thus indicating that the differences between the observed and the theoretical frequencies of males and females might rather be attributed to the overall low number of individuals. However, all sex ratios in the pharyngula group were pooled and weighted according to the number of sexed fish. The weighted sex ratios did not differ 
from the simple means, indicating that the mean sex ratio was not negatively affected by the number of observations.

The mating between normal females (XX) and a sexreversed gynogenetic male, as applied in the present study, would give $100 \%$ females in the F1-generation according to Uchida et al. [2004]. In contrast, Tong et al. [2010] assumed that sex determination in zebrafish is controlled by female-dominant genetic factors (ZW). Theoretically, the mitotic gynogenetic males would be $\mathrm{ZZ}$ or sex-reversed males $\mathrm{WW}$. The female proportion in the F1-generation would be $50 \%$ female (in case using ZZ as a father) or $100 \%$ female (in case using WW as a father). Actually, in the present study the female proportion in the F1-generation was $88 \%$ in the control groups. Neither of the assumed system, $\mathrm{XX} / \mathrm{XY}$ nor $\mathrm{ZW} / \mathrm{WW}$, is sufficient to explain the observed sex ratios obtained in our experiments. Moreover, the sex ratios in replicates of the control and the treatment groups were highly repeatable, indicating that the sex ratio at both ambient and early elevated temperatures might be under genetic control. Sex reversal during the incubation periods leads to an increase of the male proportion from $22 \%$ in control groups to balanced sex ratios $(48.25 \%, 47.54 \%$, and $52.63 \%)$ in the gastrula, segmentation, and pharyngula stage, respectively. Extending the thermal treatment starting from 5-10 hpf to 5-24 hpf and 5-48 hpf did not lead to a further increase of the male proportion (table 2), indicating that, beside the window determined by Uchida et al. [2004] from 15 to $25 \mathrm{dph}$, there is a temperature sensitive window from 5 to $10 \mathrm{hpf}$.

According to Kimmel et al. [1995], the first appearance of the germ ring is at $5.7 \mathrm{dph}\left(\right.$ at $\left.28.5^{\circ} \mathrm{C}\right)$. Generally, the effect of precocious temperature treatments on phenotypic sex has been studied only in a few fish species such as Nile tilapia, Oreochromis niloticus [Rougeot et al., 2008], and medaka, Oryzias latipes [Selim et al., 2009]. However, both groups found that heat treatment during embryogenesis can have an effect on the sex determination process in those species. In medaka, Oryzias latipes, and Hynnan ricefish, Oryzias curvinotus, a DMY-controlled XX/XY sex chromosomal mechanism has been identified [Nanda et al., 2002; Matsuda et al. 2003]. Elevated water temperatures may affect proliferation and development of germ cells [Selim et al., 2009] as well as the development of oocytes during later stages [Uchida et al., 2004]. Earlier studies deal with 2 scenarios to explain the effect of water temperature on sex determination in zebrafish, Danio rerio. The first scenario assumes an effect of high water temperatures on the survival and apoptosis

Early Elevated Rearing Temperatures

Affect Phenotypic Sex in Zebrafish of primordial germ cells [Baroiller et al., 2009b], which are essential for the formation of female gonads in zebrafish and maintain the initial ovary [Siegfried and Nüsslein-Vollhardt, 2008]. The second scenario assumes an effect of high water temperatures during the sex differentiation period (15-25 dph). During this stage the inhibition of the aromatase activity might lead to apoptosis of the primary ovary structure, which in turn leads to sexreversal of genotypic females to phenotypic males [Uchida et al., 2004].

However, Selim et al. [2009] found in medaka that a temperature increase from $27-32^{\circ} \mathrm{C}$ starting from stage 25 (beginning of sex differentiation) until stage 36 (hatching at $6 \mathrm{dpf}$ ) led to a functional masculinization of XX-females, indicating that high temperatures inhibited the proliferation and development of germ cells. Lee et al. [2009] found that in the Pufferfish, Takifugu rubripes, an early high temperature treatment $\left(32^{\circ} \mathrm{C}\right)$ induced a degeneration of the gonads, shown by a complete lack of germ cells. Morphologically, high-temperature treatments had no effect on sexual differentiation, and female ovary characteristics were maintained. Despite, the male-specific gene $d m r t 1$ was expressed in ovarian tissues with degenerated germ cells, indicating a masculinizing effect of early high temperatures. In zebrafish, $D a$ nio rerio, Siegfried and Nüsslein-Vollhardt [2008] showed that the germline is required for the ovary versus testis fate. When the germline was absent, the gonad underwent a testis fate, and normal somatic structures were developed. As the primordial germ cells are sensitive to high water temperatures [Lee et al., 2009; Selim et al., 2009], apoptosis might lead to the development of male somatic tissues [Baroiller et al., 2009b]. The fact that in the present study the major trigger on the sex ratios of the progeny could be seen already during the period from 5 to $10 \mathrm{hpf}$ might emphasize the susceptibility of germ cells to high water temperatures and their importance for the sex differentiation process in zebrafish. As suggested by Baroiller et al. [2009b], the early number of germ cells (present between 5 and $10 \mathrm{hpf}$ ) might be a critical value for the commitment to testes versus ovary fate in some fish species. At ambient temperatures, all individuals are committed to female oocyte development resulting firstly in the formation of non-functional ovaries, which then either remain ovaries or undergo testes development through regression and apoptosis of female somatic structures [Maack and Segner, 2003]. As shown by Siegfried and Nüsslein-Vollhard [2008], the absence of the germline will directly lead to the development of male somatic tissue. In the present study, it is not 
known whether the gonads of the sex-reversed fish underwent the 'normal' transition from a proto-ovary to testes, nor if the sex-reversed males were fertile (because they were sacrificed for sexing), but an effect of high early rearing temperatures on the number and survival of germ cells might have influenced the transition from proto-ovaries to testes. However, this hypothesis has to be examined in further experiments.

\section{Conclusion}

The present study showed that the phenotypic sex of zebrafish can be altered using early elevated temperatures applied for a very short period in the gastrula stage from 5 to $10 \mathrm{hpf}$. These findings indicate that 2 windows of thermal responsiveness exist in zebrafish, the first during embryonic development (5-10 hpf) and the second during the sex differentiation period (15-25 dph) [Uchida et al., 2004]. Moreover the present study proved that sex ratios in progenies derived from repeated matings of the same parents kept at ambient temperatures or treated at elevated temperatures during embryonic development are highly repeatable and thus seem to be under genetic control. Furthermore, the role of high temperatures applied during embryonic development emphasizes the need for research related to the expression of the phenotypic sex and germ cell survival. Further investigations are required to study the role of temperature treatments during embryonic development on the proliferation of germ cells in zebrafish.

\section{Acknowledgement}

The authors thank Mrs. Birgit Reinelt for her excellent technical assistance.

\section{References}

Amsterdam A, Hopkins N: Mutagenesis strategies in zebrafish for identifying genes involved in development and disease. Trends Genet 22:473-478 (2006).

Barinaga M: Zebrafish: swimming into the development mainstream. Science 250:34-35 (1990).

- Baroiller JF, D’Cotta H, Bezault E, Wessels S, Hörstgen-Schwark G: Tilapia sex determination: where temperature and genetics meet. Comp Biochem Physiol A Mol Integr Physiol 153:30-38 (2009a).

- Baroiller JF, D'Cotta H, Saillant E: Environmental effects on fish sex determination and differentiation. Sex Dev 3:118-135 (2009b).

-Cnaani A, Lee BY, Zilberman N, Ozouf-Costaz C, Hulata G, et al: Genetics of sex determination in tilapiine species. Sex Dev 2:43-54 (2008).

Conover DO: Temperature-dependent sex determination in fishes, in Valenzuela N, Lance $\mathrm{V}$ (eds): Temperature-dependent Sex Determination, pp 11-20 (Smithsonian Institution Press, Washington, DC 2004).

Devlin RH, Nagahama Y: Sex determination and sex differentiation in fish: an overview of genetic, physiological, and environmental influences. Aquaculture 208:191-364 (2002).

-Fishman MC: Genomics. Zebrafish - the canonical vertebrate. Science 294:1290-1291 (2001).

Grunwald DJ, Eisen JS: Head waters of the zebrafish. Emergence of a new model vertebrate. Nat Rev Genet 3:717-724 (2002).
Heugens EH, Hendriks AJ, Dekker T, Van Straalen NM, Admiraal W: A review of the effects of multiple stressors on aquatic organisms and analysis of uncertainty factors for use in risk assessment. Crit.Rev.Toxicol.31:247-284 (2001).

Hörstgen-Schwark G: Production of homozygous diploid zebra fish (Brachydanio rerio). Aquaculture 112:25-37 (1993).

Kahn P: Zebrafish hits the big time. Science 264 904-905 (1994).

Kimmel CB: Genetics and early development of zebrafish. Trends Genet 5:283-288 (1989).

Kimmel CB, Ballard WW, Kimmel SR, Ullmann B, Schilling TF: Stages of embryonic development of the zebrafish. Dev Dyn 203:253310 (1995).

Lamason RL, Mohideen MA, Mest JR, Wong AC, Norton HL, et al: SLC24A5, a putative cation exchanger, affects pigmentation in zebrafish and humans. Science 310:1782-1786 (2005).

Lee KH, Yamaguchia A, Rashida H, Kadomurab K, Yasumotob S, Matsuyamaa M: Germ cell degeneration in high-temperature treated Pufferfish, Takifugu rubripes. Sex Dev 3: 225-232 (2009).

Maack G, Segner H: Morphological development of the gonads in zebrafish. J Fish Biol 62:895-906 (2003).

- Matsuda M, Sato T, Toyazaki Y, Nagahama Y, Hamaguchi S, Sakaizumi M: Oryzias curvinotus has $D M Y$, a gene that is required for male development in the medaka, O. latipes. Zool Sci 20:159-161 (2003).
McLean RA, Sanders WL, Stroup WW: A unified approach to mixed linear models. Am Stat 45:54-64 (1991).

Nanda I, Kondo M, Hornung U, Asakawa S, Winkler C, et al: A duplicated copy of $D M R T 1$ in the sex-determining region of the Y chromosome of the medaka, Oryzias latipes. Proc Natl Acad Sci USA 99:1177811783 (2002).

Orban L, Sreenivasan R, Olsson PE: Long and winding roads: testis differentiation in zebrafish. Mol Cell Endocrinol 312:35-41 (2009).

Ospina-Alvarez N, Piferrer F: Temperature-dependent sex determination in fish revisited: prevalence, a single sex ratio response pattern, and possible effects of climate change. PLoS ONE 3:e2837 (2008)

Piferrer F: Endocrine sex control strategies for the feminization of teleost fish. Aquaculture 197:229-281 (2001).

-Rougeot C, Prignon C, Ngouana Kengne CV, Mélard C: Effect of high temperature during embryogenesis on the sex differentiation process in the Nile tilapia, Oreochromis $n i$ loticus. Aquaculture 276:205-208 (2008).

Rubinstein AL: Zebrafish: from disease modelling to drug discovery. Curr Opin Drug Discov Devel 6:218-223 (2003).

-Selim KM, Shinomiya A, Otake H, Hamaguchi S, Sakaizumi M: Effects of high temperature on sex differentiation and germ cell population in medaka, Oryzias latipes. Aquaculture 289:340-349 (2009). 
-Shang EH, Yu RM, Wu RS: Hypoxia affects sex differentiation and development, leading to a male-dominated population in zebrafish (Danio rerio). Environ Sci Technol 40: 31183122 (2006).

-Siegfried KR, Nüsslein-Volhard C: Germ line control of female sex determination in zebra fish. Dev Biol 324:277-287 (2008).

-Sola L, Gornung E: Classical and molecular cytogenetics of the zebrafish, Danio rerio (Cyprinidae, Cypriniformes): an overview. Genetica 111:397-412 (2001).

- Tessema M, Müller-Belecke A, HörstgenSchwark G: Effect of rearing temperatures on the sex ratios of Oreochromis niloticus populations. Aquaculture 258:270-277 (2006).
Tong SK, Hsu HJ, Chung BC: Zebrafish monosex population reveals female dominance in sex determination and earliest events of gonad differentiation. Dev Biol 344:849-856 (2010).

Traut W, Winking H: Meiotic chromosomes and stages of sex chromosome evolution in fish: zebrafish, platyfish and guppy. Chromosome Res 9:659-672 (2001).

Uchida D, Yamashita M, Kitano T, Iguchi T: Oocyte apoptosis during the transition from ovary-like tissue to testes during sex differentiation of juvenile zebrafish. J Exp Biol 205:711-718 (2002).
Uchida D, Yamashita M, Kitano T, Iguchi T: An aromatase inhibitor or high water temperature induce oocyte apoptosis and depletion of P450 aromatase activity in the gonads of genetic female zebrafish during sex-reversal. Comp Biochem Physiol A Mol Integr Physiol 137:11-20 (2004).

-Von Hertell U, Hörstgen-Schwark G, Langholz $\mathrm{HJ}$ : Family studies on genetic variability in growth and reproductive performance between and within test fish populations of the zebra fish (Brachydanio rerio). Aquaculture 85:307-315 (1990).

-Wallace BM, Wallace H: Synaptonemal complex karyotype of zebrafish. Heredity 90:136-140 (2003). 